\title{
Hypertension augments cardiac Toll-like receptor 4 expression and activity
}

\author{
Ruth Eißler ${ }^{1}$, Christoph Schmaderer ${ }^{1}$, Krisztina Rusai ${ }^{2}$, Louisa Kühne ${ }^{1}$, Daniel Sollinger ${ }^{1}$, Tobias Lahmer ${ }^{1}$, \\ Oliver Witzke ${ }^{3}$, Jens Lutz ${ }^{1}$, Uwe Heemann ${ }^{1}$ and Marcus Baumann ${ }^{1}$
}

Hypertension causes cardiac hypertrophy characterized by low-grade inflammation. Toll-like receptors (TLRs), members of the innate immune system, contribute to cardiac failure. We hypothesized that hypertension is accompanied by enhanced TLR4 expression and activity. Cardiac TLR4 expression was determined in untreated spontaneously hypertensive rats (SHR) and normotensive Wistar-Kyoto rats (WKY; 4, 8, 16 weeks). Besides, hearts of 8-week-old rats were stimulated with the endogenous TLR4 ligand heparansulfate (HS); the proinflammatory mRNA pattern was assessed (tumor necrosis factor- $\alpha$ (TNF- $\alpha$ ), interleukin (IL)-6, monocyte chemotactic protein (MCP)-1). Additionally, we induced hypertension in WKY by L-NAME ( ${ }^{\omega}{ }^{-}$-nitro-L-argininemethylester hydrochloride). In both hypertension models the effect of ramipril on TLR4 density was assessed. Cardiac TLR4 distribution was investigated by fluorescence-activated cell sorting analysis. Blood pressure (BP) and heart weight/body weight ratio (HW/BW) were elevated in SHR. Constitutive TLR4 expression was augmented in adolescent and adult, but not young SHR compared with WKY. TLR4 staining was pronounced in cardiomyocytes. HS entailed an aggravated TNF- $\alpha$ and IL- 6 mRNA response in cardiac tissue, which was significantly pronounced in SHR. Ramipril ( $10 \mathrm{mg} \mathrm{kg}^{-1}$ per day) reduced BP, HW/BW and TLR4 expression in SHR. L-NAME also augmented TLR4 expression in WKY. Ramipril ( $1 \mathrm{mg} \mathrm{kg}^{-1}$ per day) lowered BP but TLR4 expression remained unaffected. High-dose ramipril ( $10 \mathrm{mg} \mathrm{kg}^{-1}$ per day) however decreased TLR4 expression. Starting from adolescence SHR demonstrated enhanced cardiac TLR4 expression. TLR4 was also upregulated in L-NAME induced hypertension. Thus, enhanced TLR4 expression might be linked to the development and maintenance of hypertension. Finally, the antihypertensive, anti-inflammatory action of angiotensin-converting-enzyme inhibition had no effect on TLR4 expression in therapeutic doses but in a high-dose model.

Hypertension Research (2011) 34, 551-558; doi:10.1038/hr.2010.270; published online 20 January 2011

Keywords: cardiac inflammation; innate immunity; L-NAME; RAS inhibition; spontaneously hypertensive rat

\section{INTRODUCTION}

Toll-like receptors (TLRs) are important contributors of the innate immune system. ${ }^{1,2}$ Thirteen TLRs have been discovered in mammals, which can detect multiple pathogen associated molecular patterns in terms of exogenous ligands. TLR-mediated signaling mainly activates nuclear factor $\kappa \mathrm{B}$, which has a critical role in the regulation of genes mainly involved in immune and inflammatory responses, cell death and survival. ${ }^{2}$

It has been shown that TLR4 is involved in cardiovascular disease. The receptor is upregulated after myocardial infarction in mice $^{3}$ and has a role in myocardial dysfunction during bacterial sepsis and myocardial injury following ischemia/reperfusion. ${ }^{4}$ Post infarct TLR4 regulates maladaptive left ventricular remodeling, probably via inflammatory cytokine production and matrix degradation..$^{5}$ Besides, tissue TLR4 expression is increased in human heart failure and ischemic hearts. Furthermore, interaction with the TLR4-mediated, MyD88 (myeloid differentiation primary response gene 88) -dependent nuclear factor $\kappa \mathrm{B}$ pathway modulates the hypertrophic response of cardiomyocytes. ${ }^{6,7}$

Hypertension in turn is characterized by a progredient cardiac hypertrophy, which is associated with low-grade inflammation., ${ }^{8,9}$ Therefore, spontaneously hypertensive rats (SHRs) start to exhibit impaired myocardial contractile function and ventricular fibrosis at advanced age after a prolonged period of established hypertension. ${ }^{10}$ Moreover, several studies implicated a substantial role of inflammation on BP (blood pressure) development itself.9,11

TLR4 specifically recognizes lipopolysaccharide from Gramnegative bacteria and endogenous ligands such as heparansulfate (HS) and heat-shock proteins. ${ }^{7,12}$ HS activates TLR4 in the same way as the exogenous ligand lipopolysaccharide. ${ }^{13}$ It can be a breakdown product after cell damage and tissue injury and as specific activator of TLR4 it induces systemic inflammatory responses. ${ }^{14,15}$

The role of the innate immune system, that is TLR4, in hypertension is still uncertain. Importantly, hypertension is associated with

${ }^{1}$ Department of Nephrology, Klinikum rechts der Isar, Technical University Munich, Munich, Germany; ${ }^{2}$ First Department of Pediatrics, Semmelweis University Budapest, Budapest, Hungary and ${ }^{3}$ Department of Nephrology, University Essen, Essen, Germany

Correspondence: Dr M Baumann, Department of Nephrology, Klinikum rechts der Isar, Technische Universität München, Ismaninger Street 22, 81675 München, Germany. E-mail: marcus.baumann@|rz.tum.de

Received 9 June 2010; revised 2 November 2010; accepted 14 November 2010; published online 20 January 2011 
low-grade inflammation. Furthermore, TLR4 contributes to systemic inflammation and cardiac hypertrophy. Thus, we hypothesized that in the state of developing and established hypertension TLR4 expression and activity is enhanced. Therefore we investigated the cardiac TLR4 expression and inflammatory status in two independent models of hypertension. We further tested the hypothesis whether antihypertensive and excessive angiotensin-converting-enzyme (ACE) inhibition reduces TLR4 expression as ACE inhibition includes anti-inflammatory action.

\section{METHODS}

\section{Experimental setting}

Twenty-four SHRs and 24 Wistar-Kyoto rats (WKY) aged 4, 8 and 16 weeks $(n=8$ per age and strain, untreated) were characterized for TLR4. Another group of 6-week-old SHR $(n=8)$ received $10 \mathrm{mg} \mathrm{kg}^{-1}$ per day ramipril (high dose) by oral gavage for 2 weeks. In a second hypertensive model, L-NAME was administered at a dose of $25 \mathrm{mg} \mathrm{kg}^{-1}$ per day by gavage to 8-week-old WKY for 2 weeks $(n=18)$, whereas six WKY were additionally used as normotensive controls without L-NAME.

L-NAME treated WKY received additionally $1 \mathrm{mg} \mathrm{kg}^{-1}$ per day ramipril (normal dose), $10 \mathrm{mg} \mathrm{kg}^{-1}$ per day ramipril (high dose) or vehicle by oral gavage ( $n=6$ per group). All rats were housed under controlled conditions of temperature $\left(21^{\circ} \mathrm{C}\right)$ and light (12-h light/dark cycle, $\left.07.00-19.00 \mathrm{~h}\right)$ and were maintained on normal rat chow and water ad libitum. All experiments were approved by the local committee and performed in accordance with institutional guidelines.

In all rats, mean intra-arterial BP was measured through a heparinized $\left(5 \mathrm{U} \mathrm{ml}^{-1}\right)$ indwelling polyethylene catheter that was introduced into the left femoral artery under isofluran anesthesia. At the end of the observation period heart weight/body weight ratio (HW/BW) was determined. Hearts and spleens were snap frozen for western blotting. Hearts were also used freshly for in vitro experiments or fluorescence-activated cell sorting (FACS) analysis or paraffin embedded for immunohistochemistry of TLR4.

\section{Western blotting and enzyme-linked immunosorbent assay} Snap-frozen hearts and spleens were lysed in RIPA buffer $(50 \mathrm{~mm}$ Tris- $\mathrm{HCl} \mathrm{pH}$ 7.5, $150 \mathrm{~mm} \mathrm{NaCl}, 10 \mathrm{~mm} \mathrm{NaF}, 1 \mathrm{~mm} \mathrm{Na} \mathrm{VO}_{4}, 2 \mathrm{~mm}$ EDTA, 1\% NP-40 and protease inhibitors) for protein extraction. Protein concentrations were measured using Bradford protein dye reagent (BCA Protein Assay Reagent Kit, Pierce, Rockford, IL, USA). After separation by $10 \%$ SDS polyacrylamide electrophoresis proteins were transferred electrophoretically onto nitrocellulose membranes $(0.2 \mu \mathrm{m}$, Amersham, Buckinghamshire, UK). Next, membranes were blocked with $5 \%$ non-fat dried milk in Tris-buffered saline and Tween 20 and probed with primary antibodies against TLR4 (1:200, Santa Cruz Biotechnology, Santa Cruz, CA, USA) and glyceraldehyde-3-phosphate dehydrogenase (1:10 000, US Biological, Swampscott, MA, USA). Antibody-antigen complexes were detected using horseradish peroxidase-conjugated antibodies (anti-rabbit immunoglobulin G; donkey anti-goat immunoglobulin G; DAKO, Glostrup, Denmark), visualized with an enhanced chemiluminescence detection kit (Amersham Pharmacia Biotech, Buckinghamshire, UK) and quantified with Kodak Digital Science IS440 CF software (Kodak, Stuttgart, Germany). The intensities of the bands were normalized for glyceraldehyde-3-phosphate dehydrogenase and were expressed as fold increase over control WKY.

Tumor necrosis factor- $\alpha$ (TNF- $\alpha$ ) levels in cardiac tissue were measured by enzyme-linked immunosorbent assay according to the manufacturer's protocol (R\&D Systems, McKinley Place NE, MN, USA).

\section{In vitro experiment and real-time $\mathrm{PCR}$}

Hearts from 8-week-old SHR and WKY ( $n=4$ per group) were transversally sliced and exposed to collagenase digestion (Invitrogen, Darmstadt, Germany; $1 \mathrm{mg} \mathrm{ml}^{-1}, 1 \mathrm{~h}, 37^{\circ} \mathrm{C}$ ). The cardiac lysate, a single cell suspension mainly consisting of cardiomyocytes and endothelial cells, was transferred in a medium consisting of Dulbecco's modified Eagle's medium, $0.5 \%$ glutamine, $5 \%$ fetal calf serum, $0.125 \%$ HEPES $1 \mathrm{~m}$ and $0.5 \%$ penicillin/streptomycin (all from Sigma Chemicals, St Louis, MO, USA). The cardiac lysate was then stimulated with HS (Sigma Chemicals; $10 \mu \mathrm{g} \mathrm{ml}^{-1}$; negative control: $0 \mu \mathrm{g} \mathrm{ml}^{-1}$ ) for $4 \mathrm{~h}$ at $37^{\circ} \mathrm{C}$ in a humidified atmosphere comprising $95 \%$ air and $5 \% \mathrm{CO}_{2}$. The
mRNA was extracted from the cell pellet (RNeasy Mini Kit, Qiagen, Hilden, Germany) and transcribed into cDNA with iScrpit Synthesis kit (Qiagen). Quantitative real-time PCR was performed with IQ SYBR Green Supermix (BIO-RAD, Qiagen) using gene-specific primers (250 ng; Sigma Chemicals). Primers against the selected genes of TNF- $\alpha$ (up: $5^{\prime}$-CTATGTGCTCCTCACCC ACA-3'; down: 5'-AAGTAGACCTGCCCGGACTC- $3^{\prime}$; $59^{\circ} \mathrm{C}$ ), interleukin (IL)-6 (up: 5'-ATACCACCCACAACAGACCA-3'; down: 5'-CCAGAAGACCAGAGC AGATT- $3^{\prime} ; 60^{\circ} \mathrm{C}$ ) and monocyte chemotactic protein (MCP)-1 (up: $5^{\prime}$-CAAT GAGTCGGCTGGAGAAC- $3^{\prime}$; down: 5'-GCTTGAGGTGGTTGTGGAAA- $3^{\prime}$; $60^{\circ} \mathrm{C}$ ) were investigated. Glyceraldehyde-3-phosphate dehydrogenase $(G A P D H)$ was used as a housekeeping gene (up: 5'-ATGCTTGTGATGGGTGTGAA-3'; down: 5-'GGATGCAGGGATGATGTTCT- $3^{\prime}$; $55^{\circ} \mathrm{C}$ ). Cardiac mRNA was extracted from snap-frozen hearts following the same protocol. To assess TLR4 mRNA expression in hearts the following primers were used: TLR4 (up: 5-'GTG GGTCAAGGACCAGAAAA-3'; down: 5-'GGCTACCACAAGCACACTGA-3'; $55^{\circ} \mathrm{C}$ ) and phosphoglucokinase-1 (housekeeping gene) (up: 5-'CGGAGAAC ACGCCACTTG-3'; down: 5-'AAGGCAGGAAAATACTAAACA; $\left.62^{\circ} \mathrm{C}\right)$. Primers for TNF- $\alpha$, IL- 6 and MCP- 1 were the same as in the cell culture experiment.

\section{Immunohistochemical analysis}

After fixation with $4 \%$ paraformaldehyde, hearts were embedded in paraffin, cut into $4 \mu \mathrm{m}$ thick slices and stained for TLR4. The sections were labeled by the sequential application of a primary rabbit anti-TLR4 antibody (1:100 in phosphate-buffered saline) and a link-antibody (anti-rabbit immunoglobulins G, 1:100 in phosphate-buffered saline; both from Vector, Burlingame, CA, USA). Dilution of the streptavidin solution (Vector) used for visualization was 1:100. Preparations were analyzed with an Olympus microscope (Olympus, Hamburg, Germany) and digitally photographed at a $\times 20 / \times 40$ magnification using the image processing software Image Pro Plus (Media Cybernetics, Bethesda, MD, USA).

\section{FACS analysis of cardiac cells}

Two-colour flow-cytometric analysis (FACS) was used to identify CD45/TLR4expressing cells in the heart. The tissue was submitted to collagenase digestion $\left(2 \mathrm{mg} \mathrm{ml}^{-1} ; 1 \mathrm{~h}, 37^{\circ} \mathrm{C}\right)$ to get a single cell suspension. Cells were resuspended in $100 \mu \mathrm{l} \mathrm{FACS}$ buffer and placed on ice. Fluorescein isothiocyanate anti-rat CD45R (eBioscience, San Diego, CA, USA) and anti-TLR4 (unlabeled; Santa Cruz Biotechnology) were added (1:200; incubation time: $45 \mathrm{~min}$ ). After washing with FACS buffer, the secondary antibody for TLR4 (anti-rabbit-PE, Santa Cruz Biotechnology) was added (1:200; incubation time: $45 \mathrm{~min}$ ). Analysis was done on a Beckman Coulter flow cytometer (Beckman Coulter, Krefeld, Germany). Before running the samples on the flow cytometer, propidium iodide (1:1000 of a $1 \mathrm{mg} \mathrm{ml}^{-1}$ stock; Sigma Chemicals) was added to label dead cells. Data were analyzed using Beckman Coulter Software (Beckman Coulter). Dead cells were excluded using propidium iodide staining. A positive control for anti-rat CD45 antibody and anti-rat TLR4 antibody was performed on rat spleen cells.

\section{Statistics}

Comparison between normotensive and hypertensive strains was performed with student's $t$-test or $\chi^{2}$-test, were appropriate. Group differences between pharmacological treatments in L-NAME-treated WKY were compared by analysis of variance and a post-hoc Dunnett's $t$-test. $P$ values of 0.05 or less were regarded to indicate statistical significance. Values are means \pm s.e.m.

\section{RESULTS}

Untreated SHR of all ages demonstrated higher BP values and a higher HW/BW ratio than untreated WKY, high-dose ramipril significantly reduced BP and HW/BW in SHR (Table 1). Cardiac immunohistochemistry of TLR4 in adult WKY and SHR demonstrated an enhanced patchy distribution of TLR4 staining predominantly in cardiomyocytes of SHR, which was reversed by ACE inhibition with high-dose ramipril ( $10 \mathrm{mg} \mathrm{kg}^{-1}$ per day). TLR4 positive cardiomyocytes in untreated SHR where homogenously stained including the cytoplasm and were hypertrophic. TLR4 staining in WKY was restricted to less cardiomyocytes and the intensity in each single cardiomyocyte was 
Table 1 MAP and HW/BW in untreated young, adolescent and adult WKY and SHR and ramipril-treated SHR (10 mg kg ${ }^{-1}$ per day)

\begin{tabular}{|c|c|c|c|c|c|c|c|}
\hline & \multicolumn{2}{|c|}{ Young } & \multicolumn{2}{|c|}{ Adolescent } & \multicolumn{2}{|c|}{ Adult } & \multirow{2}{*}{$\begin{array}{l}\text { Adolescent } \\
\text { SHR+ramipril }\end{array}$} \\
\hline & $W K Y$ & $S H R$ & $W K Y$ & $S H R$ & $W K Y$ & $S H R$ & \\
\hline HW/BW $\left(\mathrm{g} \mathrm{kg}^{-1}\right)$ & $4.5 \pm 0.2$ & $5.2 \pm 0.3^{*}$ & $3.4 \pm 0.1$ & $3.8 \pm 0.3^{*}$ & $2.7 \pm 0.04$ & $3.4 \pm 0.4^{*}$ & $3.4 \pm 0.1^{\#}$ \\
\hline
\end{tabular}

Abbreviations: HW/BW: heart weight/body weight; MAP, mean arterial pressure, SHR, spontaneously hypertensive rats; WKY, Wistar-Kyoto rats. ${ }^{*} P<0.05$ vs. WKY; ${ }^{P}<0.05$ vs. adolescent SHR.
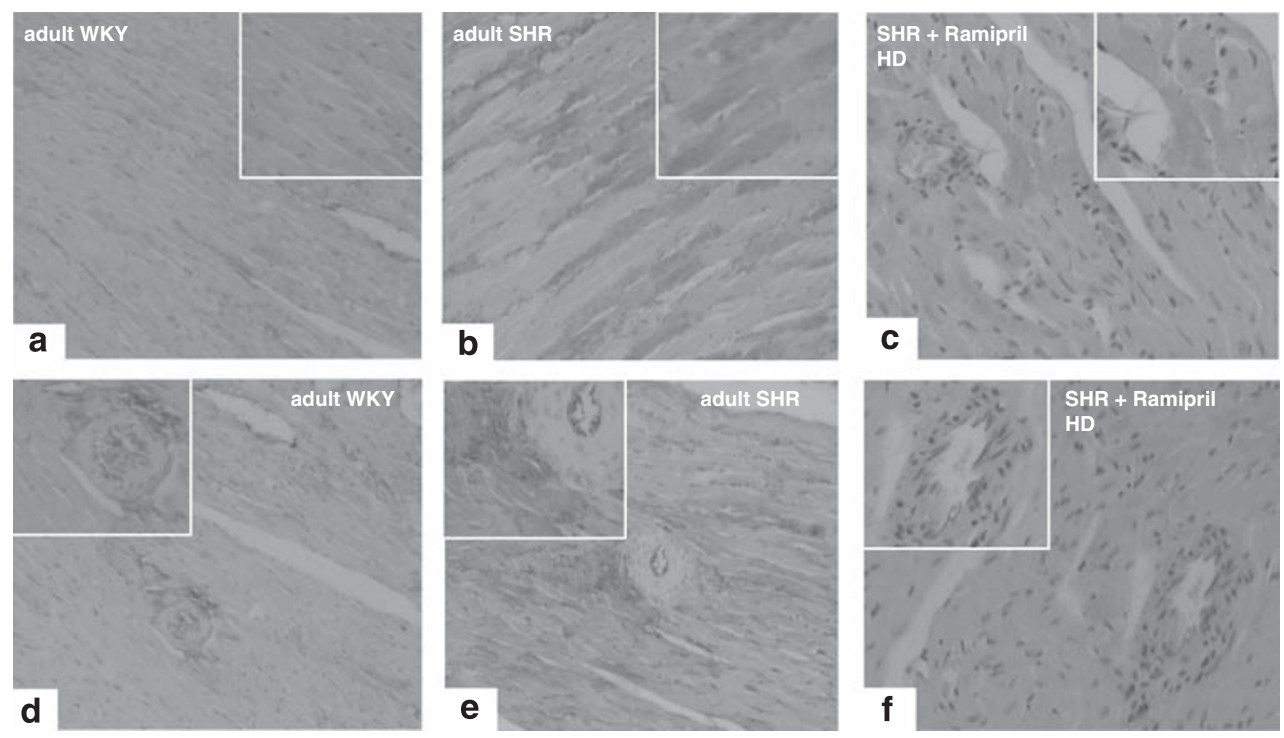

Figure 1 TLR4 protein in rat myocardium detected by immunohistochemistry (magnification $\times 20$, inset $\times 40$ ). SHR showed an increased TLR4 staining of hypertrophic cardiomyoctes compared with control, which was reversed by a high dose of ramipril ( $10 \mathrm{mg} \mathrm{kg}^{-1}$ per day) (a-c). Perivascular inflammation in the myocardium was also TLR4 positive in adult SHR (e) compared with adult WKY (d) and ramipril treated SHR (f). HD, high dose. A full color version of this figure is available at the Hypertension Research journal online.

lower as compared with SHR. Significantly reduced TLR4 staining and cardiac hypertrophy was observed in the ramipril treated SHR (Figures $1 \mathrm{a}-\mathrm{c}$ ). Besides, untreated SHR were additionally characterized by an augmented perivascular TLR4 staining as compared with WKY, which was reversed by ramipril (Figures $1 \mathrm{~d}-\mathrm{f}$ ). The augmented TLR4 staining pattern in cardiac tissue of untreated adult SHR was confirmed on protein level by western blotting (Figure 2a) and on mRNA level by real-time PCR. Cardiac TNF- $\alpha$ and MCP-1 mRNA levels were also determined by real-time PCR (Figure $2 b$ ).

Constitutive TLR4 expression did not differ in hearts of 4-week-old WKY and SHR with respect to mRNA and protein level (Figure 2c). However, in adolescent, that is, 8-week-old animals, there was a significant difference in TLR4 expression on mRNA and protein level, with SHR showing more cardiac TLR4 than normotensive controls (Figure 2d). The protein amount of cardiac TNF- $\alpha$ was similar in 4,8 and 16-week-old SHR as shown by enzyme-linked immunosorbent assay (Figure 2e).

High-dose ramipril $\left(10 \mathrm{mg} \mathrm{kg}^{-1}\right.$ per day) significantly reduced TLR4 on the mRNA level in 8-week-old SHR whereas mRNA levels of TNF- $\alpha$, MCP-1 and IL- 6 were not affected by ACE inhibition (Figure 2f). IL-6 was expressed in very low amounts (data not shown). Western blotting of the spleen did not reveal differences in TLR4 density between WKY and SHR in any age group (data not shown).

The proinflammatory activity of TLR 4 was assessed by adding the endogenous ligand HS to cardiac tissue lysate in adolescent animals. HS initiated a proinflammatory mRNA pattern after $4 \mathrm{~h}$ with respect to TNF- $\alpha$ and IL-6 mRNA levels in SHR as compared with WKY. MCP-1 mRNA levels were similar in both rat strains (Figure 3).

In the second hypertension model, L-NAME induced a significant BP increase in WKY (L-NAME-WKY: $124 \pm 8 \mathrm{mmHg}$ vs. WKY: $101 \pm 8 \mathrm{~mm} \mathrm{Hg} ; P<0.05$; Table 2). Additional treatment with the therapeutic dose of ramipril ( $1 \mathrm{mg} \mathrm{kg}^{-1}$ per day) and the excessive dose of ramipril $\left(10 \mathrm{mg} \mathrm{kg}^{-1}\right.$ per day) antagonized the L-NAME-induced BP increase $(99 \pm 10 \mathrm{~mm} \mathrm{Hg}$ therapeutic dose; $95 \pm 13 \mathrm{~mm} \mathrm{Hg}$ high dose; $P<0.05$ compared with L-NAME treated WKY; Table 2).

L-NAME treated WKY demonstrated an enhanced TLR4 staining compared with vehicle treated WKY. The distribution was predominantly located in cardiomyocytes (Figures $4 \mathrm{a}$ and b). Perivascular TLR4 was also significantly increased in L-NAME treated WKY (Figures $4 \mathrm{c}$ and $\mathrm{d}$ ). WKY receiving L-NAME and ramipril $1 \mathrm{mg} \mathrm{kg}^{-1}$ per day showed a similar staining pattern as L-NAME WKY (Figures 4e and $\mathrm{f}$ ). In accordance with the immunohistochemistry, TLR4 mRNA and protein levels of cardiac tissue showed no difference between LNAME WKY and L-NAME WKY with concomitant ramipril normaldose treatment (Figures $5 \mathrm{a}$ and $\mathrm{b}$ ). However, the TLR4 staining was significantly reduced after high-dose ramipril (Figures $4 \mathrm{~g}$ and $\mathrm{h}$ ), as was the cardiac TLR4 mRNA expression (Figure 5c).

Figure $6 \mathrm{a}$ shows an anti-CD45 fluorescein isothiocyanate, antiTLR4 PE double stain of SHR heart tissue analyzed by FACS measurement and the resulting histograms (Figures $6 \mathrm{~b}$ and $\mathrm{c}$ ). A lack of CD45-positive cells was seen, suggesting a predominant role of the cardiomyocytes as TLR4-expressing cells. 

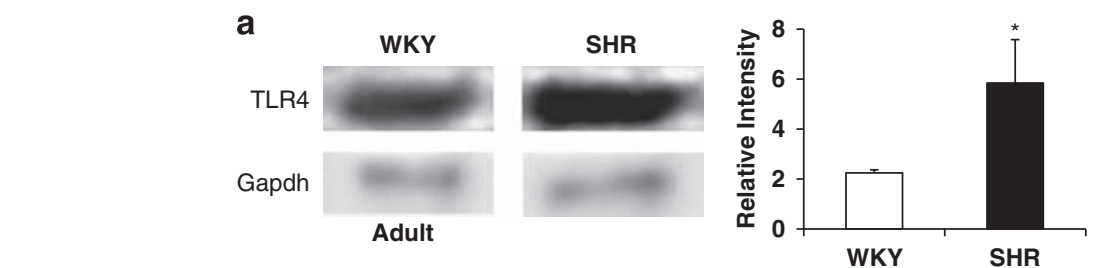

b

mRNA expression in adult animals
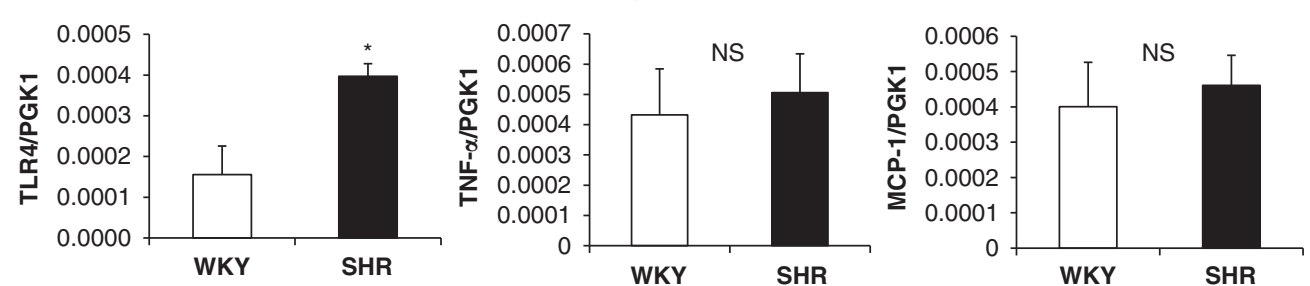

C
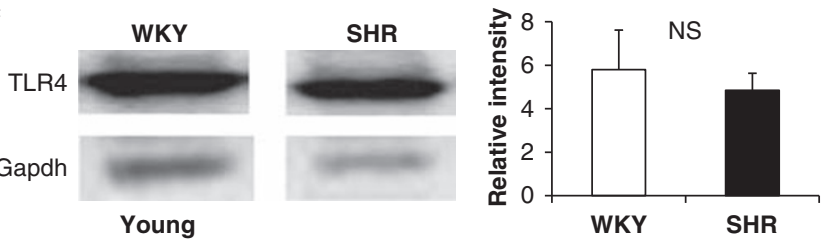

d

WKY

TLR4

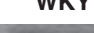

Gapdh
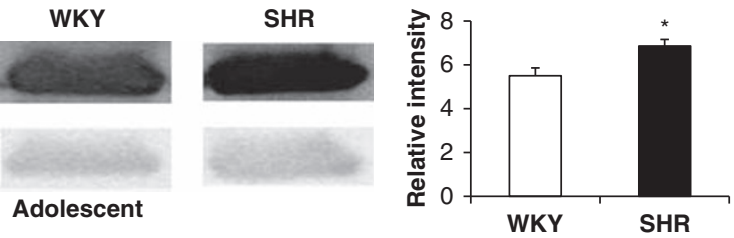

e

Adolescent
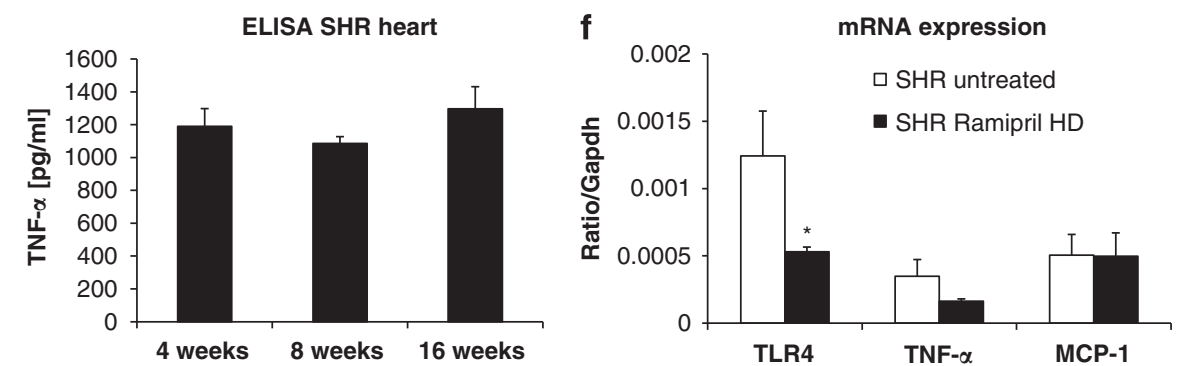

Figure 2 TLR4 western blotting of cardiac tissue lysate of adult WKY and SHR (a). Band intensity was determined by densitometry. TLR4, TNF- $\alpha$ and MCP-1 mRNA expression in adult SHR was confirmed by real-time (RT) PCR (b). TLR4 western blotting of cardiac tissue lysate of young WKY and SHR (4 weeks) and of adolescent WKY and SHR ( 8 weeks) was also analyzed (c, d). The amount of TNF- $\alpha$ did not change during the development of hypertension as shown by the time course of cardiac TNF- $\alpha$ in 4-, 8- and 16-week-old untreated SHR measured by enzyme-linked immunosorbent assay (e). Cardiac TLR4, TNF- $\alpha$ and MCP-1 mRNA expression in adolescent untreated and ramipril high-dose treated SHR was analyzed by RT-PCR (f). $\left({ }^{*} P<0.05\right)$. HD, high dose.
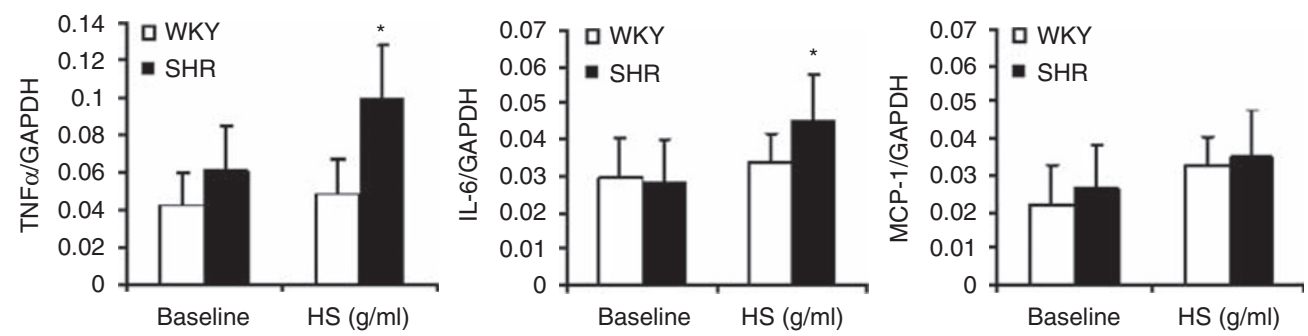

Figure 3 Proinflammatory mRNA pattern of cardiac tissue after $4 \mathrm{~h}$ incubation with $10 \mu \mathrm{g} \mathrm{ml}^{-1} \mathrm{HS}\left({ }^{*} P<0.05\right)$.

\section{DISCUSSION}

Starting from adolescence SHR demonstrated significantly enhanced constitutive cardiac TLR4 expression, predominantly involving cardiomyocytes. This pattern was reproducible in L-NAME induced hypertension. The enhanced TLR4 expression was functionally associated with an augmented TLR4-dependent pro-inflammatory activity. This suggests that TLR4 is associated with low-grade inflammation in hypertension. Finally, the antihypertensive and anti-inflammatory 
Table 2 MAP and HW/BW in untreated, L-NAME-treated and L-NAME+ramipril-treated WKY ( $1 \mathrm{mg} \mathrm{kg}^{-1}$ per day; $10 \mathrm{mg} \mathrm{kg}^{-1}$ per day)

\begin{tabular}{lcccc}
\hline & Untreated & Vehicle + L-NAME & Ramipril $\left(1 \mathrm{mg} \mathrm{kg}^{-1}\right.$ per day $)+L-N A M E$ & Ramipril (10 mg kg-1 per day $)+L-N A M E$ \\
\hline MAP $\left(\mathrm{mm} \mathrm{Hg}^{2}\right)$ & $101 \pm 8$ & $124 \pm 8^{*}$ & $99 \pm 10^{\#}$ & $95 \pm 13^{\#}$ \\
HW/BW $\left(\mathrm{g} \mathrm{kg}^{-1}\right)$ & $2.8 \pm 0.15$ & $3.5 \pm 0.2^{*}$ & $3.1 \pm 0.2^{\#}$ & $2.9 \pm 0.5^{\#}$ \\
\hline
\end{tabular}

Abbreviations: HW/BW, heart weight/body weight; MAP, mean arterial pressure; WKY, Wistar-Kyoto rats.

${ }^{*} P<0.05$ vs. untreated; ${ }^{\#} P<0.05$ vs. vehicle+L-NAME.

action of ACE inhibition had an effect on TLR4 expression only in a high-dose model, exceeding the therapeutic, antihypertensive dose, whereas a therapeutic dose of ramipril was not able to reduce enhanced TLR4 density.

The first major finding of this study is that cardiac TLR4 expression is enhanced in hypertension. Interestingly, only a brief period of elevated BP was needed to induce the enhanced cardiac TLR4 expression as this pattern was already present in adolescent SHR, which start to show elevated BP between the age of 5 to 8 weeks, ${ }^{16}$ and after two weeks of L-NAME treatment. Moreover, immunohistochemistry revealed that the enhanced TLR4 expression was predominantly related to an augmented presence of TLR4 in cardiomyocytes rather than infiltrating cells. The predominant role of the cardiomyocyte was further strengthened by the fact that (1) the spleen did not show augmented TLR4 expression in established hypertension, (2) MCP-1 mRNA levels in the hearts of adolescent and adult WKY and SHR were similar and (3) FACS analysis demonstrated that only a small part of the TLR4-positive cardiac cells were also CD45-positive, that is, not leukocytes but rather cardiomyocytes expressed TLR4. The ability of cardiomyocytes to become TLR4 positive has been initially described by Frantz et al. in the failing heart ${ }^{3}$ who observed a focal and patchy distribution of TLR4-positive cells in the murine myocardium after myocardial infarction remote from sites of the ischemic injury. Our data suggest that already brief BP elevation enables cardiomyocytes to become TLR4 positive. As hypertension results in cardiac hypertrophy with an inflammatory component leading to cardiac failure in the long term ${ }^{17-19}$ we asked how TLR4 may participate in this process. This might be related to the proinflammatory action of TLR4, which has been described for VSMC. ${ }^{20}$

Hypertension is associated with low-grade inflammation. It is known that in the very early state of developing hypertension, inflammatory pathways are already activated.

In particular SHR are characterized by enhanced oxidative stress and nuclear factor $\kappa \mathrm{B}$ activity, which become significant in adolescent SHR whereas prehypertensive animals are not yet prone to the production of reactive oxygen species. ${ }^{21}$ This is consistent with the finding that the activity of the glutathione peroxidase, which protects from oxidative damages, is significantly reduced in kidneys of SHR from the age of 8 week onwards. ${ }^{22}$ Besides, obvious cardiac hypertrophy is developed around week 8 , for example, together with an activation of the cardiac endothelin system. ${ }^{23}$ The state of developing hypertension reflects the similar time period in which the first significant rise of cardiac TLR4 expression was observed. In young SHR, that is, before the rapid phase of pathological BP increase, TLR4 was not yet upregulated. However cardiac TLR4 was upregulated in adolescent and adult animals, independent of the inflammatory markers TNF- $\alpha$, MCP-1 and IL- 6 . This leads to the assumption that TLR4 upregulation goes along with the increase of blood pressure but its expression is still kept on a normal level in very young animals.

The associated chronic low-grade inflammation damages cells that release substances, which partially react as endogenous TLR4 ligands. $^{24,25}$ One of these substances, HS, was added to cardiac cell lysate of SHR and WKY to mimic a pronounced cellular damage. The observed TLR4-mediated proinflammatory reaction was enhanced in SHR, that is, the response was significantly augmented in SHR compared with WKY. This suggests that TLR4 signaling in SHR can promote a stronger inflammatory response based on cell damage as for instance induced by a prolonged period of elevated BP. Therefore, TLR4 may accelerate cardiac damage in particular in advanced stages of hypertension when cellular damage leads to an enhanced level of circulating endogenous TLR4 ligands. As we observed a strong inflammatory response in hearts of SHR after direct HS stimulation, but neither a difference in mRNA levels of inflammatory cytokines between untreated adult WKY and SHR, nor an age-related increase in cardiac TNF- $\alpha$ protein level in SHR, we conclude, that only high doses of TLR4 ligands exert this inflammatory effect. In our case we might have a chronic low-grade inflammation with normal inflammatory cytokine pattern in the heart, at least till the age of 16 weeks.

The role of inflammation in hypertension and related target organ damage is widely accepted and finds its therapeutic consequence in the use of antihypertensive substances, which additionally include antiinflammatory action such as blockers of the renin-angiotensin system (RAS). Therefore we asked whether the antihypertensive and antiinflammatory action of ACE inhibition may reverse the pronounced TLR4 expression in cardiomyocytes. Despite sufficient BP lowering with the therapeutic dose of $1 \mathrm{mg} \mathrm{kg}^{-1}$ per day ramipril, we did not find a reduction of TLR4 expression and change in staining pattern. This finding stands in contrast to the in vitro finding of Lv et al. who observed a reduction in AngII-induced TLR4 expression after reninangiotensin system blockade with a therapeutic dose of candesartan in mesangial cells. ${ }^{26}$ Our results however showed that an ultra high dose of $10 \mathrm{mg} \mathrm{kg}^{-1}$ per day ramipril led to a TLR4 downregulation on the mRNA and protein level, that is we conclude that this is a dosedependent effect. There might be a direct effect of the ACE inhibitor on TLR4 expression. This means that downregulation of TLR4 by ramipril can not only be a result of BP lowering as short-term normaldose antihypertensive action had no effect on TLR4 expression but a high dose downregulated TLR4 to basal level. Moreover TNF- $\alpha$ mRNA was downregulated by high-dose ramipril in SHR whereas the MCP-1 levels did not differ; we conclude that immune cells have a minor role in this context. Dose-related effects of drugs on TLR4expression and inflammation have also been described by others; Ji et al. describe that the hypolipidemic agent fenofibrate has a direct effect on TLR4 expression and reduces AngII-induced mRNA and protein expression of TLR4 in concentration-dependent manner. ${ }^{27}$ Burgess et al. found an advantage in the use of supramaximal doses of candesartan in proteinuric renal diease. ${ }^{28}$

TLR4 antibodies have been tested in sepsis and chronic bowel disease $^{29-31}$ and have shown promising results. We speculate that direct blockade of TLR4 action by using a neutralizing antibody in vivo may also ameliorate hypertensive low-grade inflammation independent of renin-angiotensin system blockade in order to hamper the development of cardiac failure. 

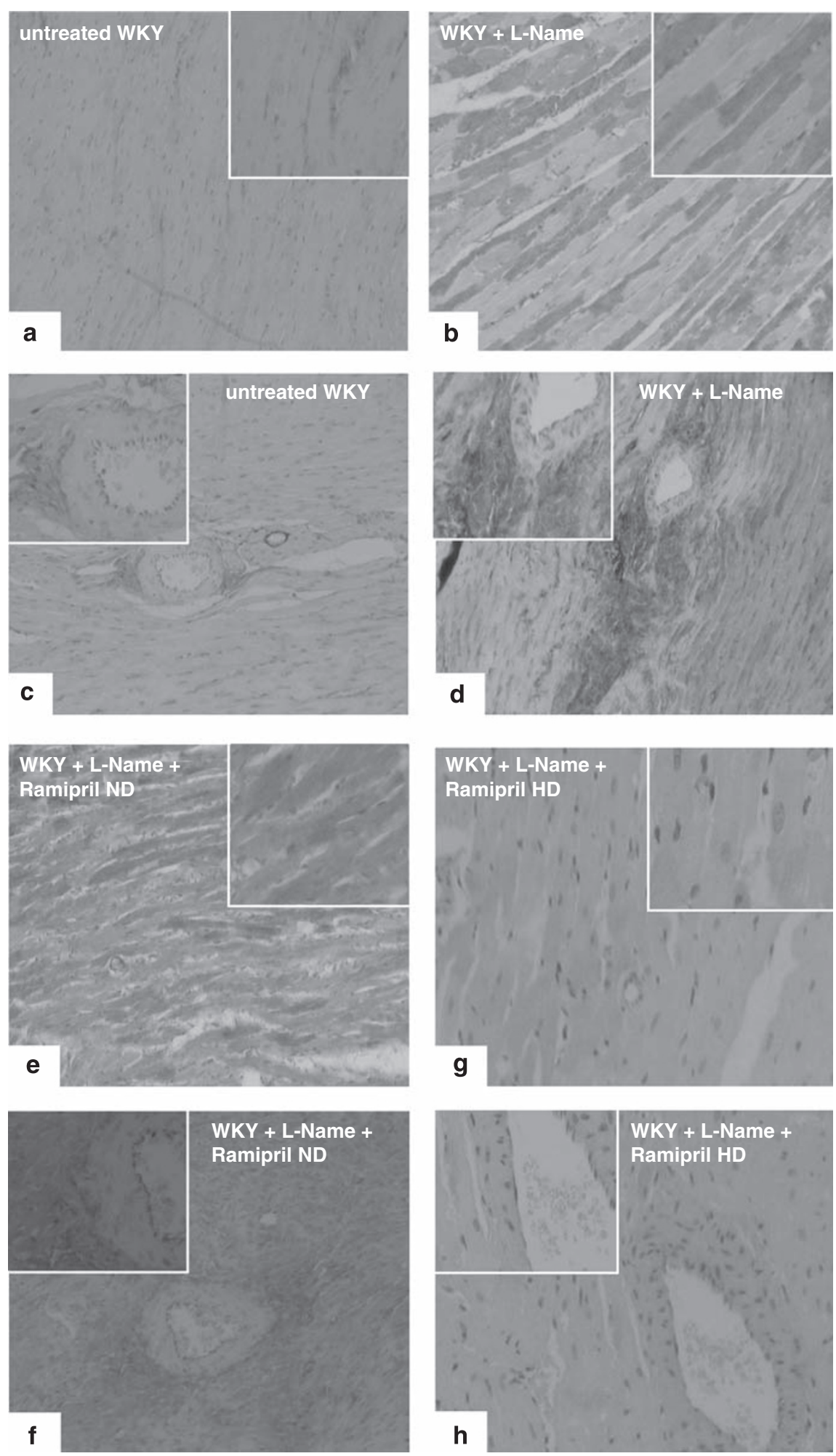

Figure 4 TLR4 protein in myocardium of vehicle-, L-NAME- and ramipril-treated WKY detected by immunohistochemistry (magnification $\times 20$, inset $\times 40$ ). Two weeks of L-NAME treatment resulted in increased cardiac TLR4 staining of hypertrophic cardiomyocytes (a, b) and in TLR4 positive perivascular inflammation (c, d); ramipril normal dose did not change the TLR4 staining pattern (e, f) whereas ramipril high dose significantly reduced the TLR4 staining $(\mathbf{g}, \mathbf{h})$. ND, normal dose; HD, high dose. A full color version of this figure is available at the Hypertension Research journal online.

In summary this study demonstrated in two independent hypertensive models an early appearance of TLR4, which was pronounced in cardiomyocytes. This pattern was associated with an augmented
TLR4-dependent proinflammatory activity after in vitro TLR4 activation. Consequently, we suggest that there might be a link between the pathogenesis of hypertension and the innate immune 
a

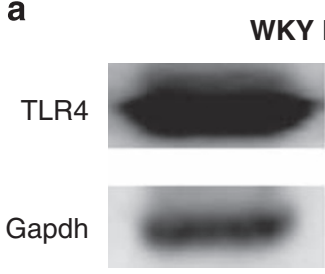

Vehicle
WKY L-NAME
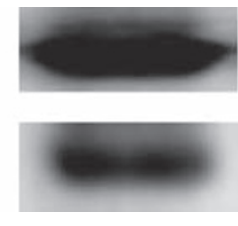

Ramipril ND
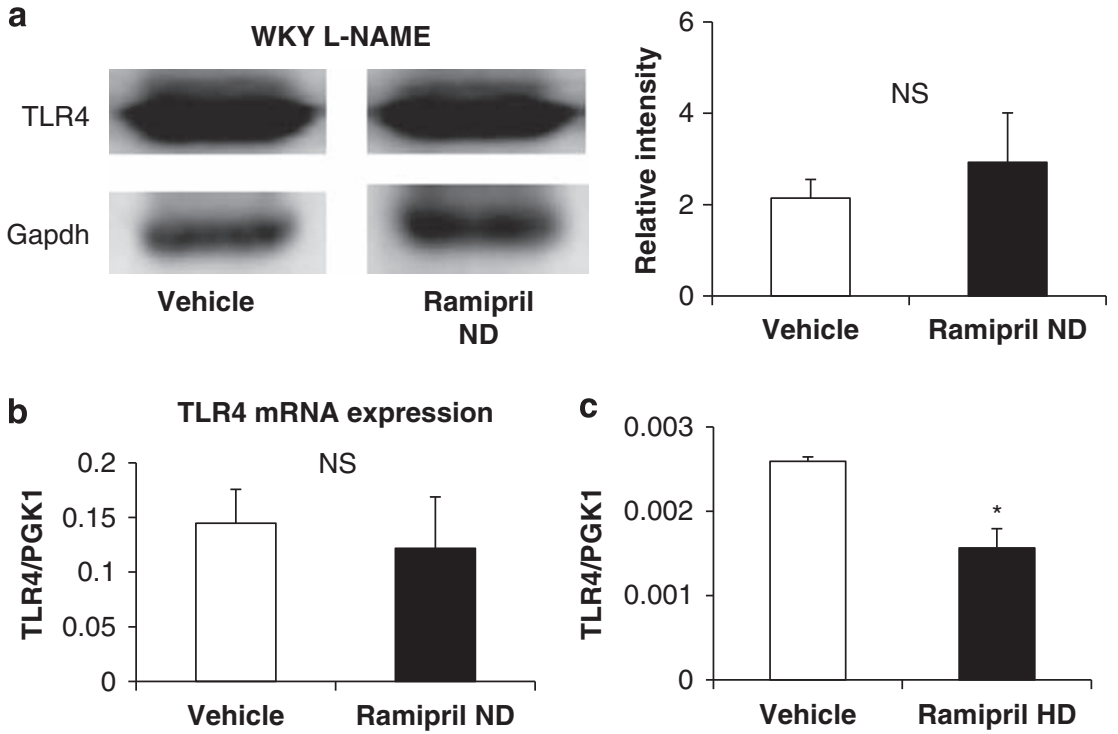

Figure 5 Western blotting of L-NAME and L-NAME+ramipril-treated WKY. Antihypertensive treatment with ramipril normal dose had no effect on TLR4 density in L-NAME induced hypertension in WKY (a). TLR4 mRNA expression confirmed this result (b). Ramipril high dose reduced TLR4 mRNA expression in hearts of L-NAME treated WKY (c). ( $\left.{ }^{*} P<0.05\right)$.
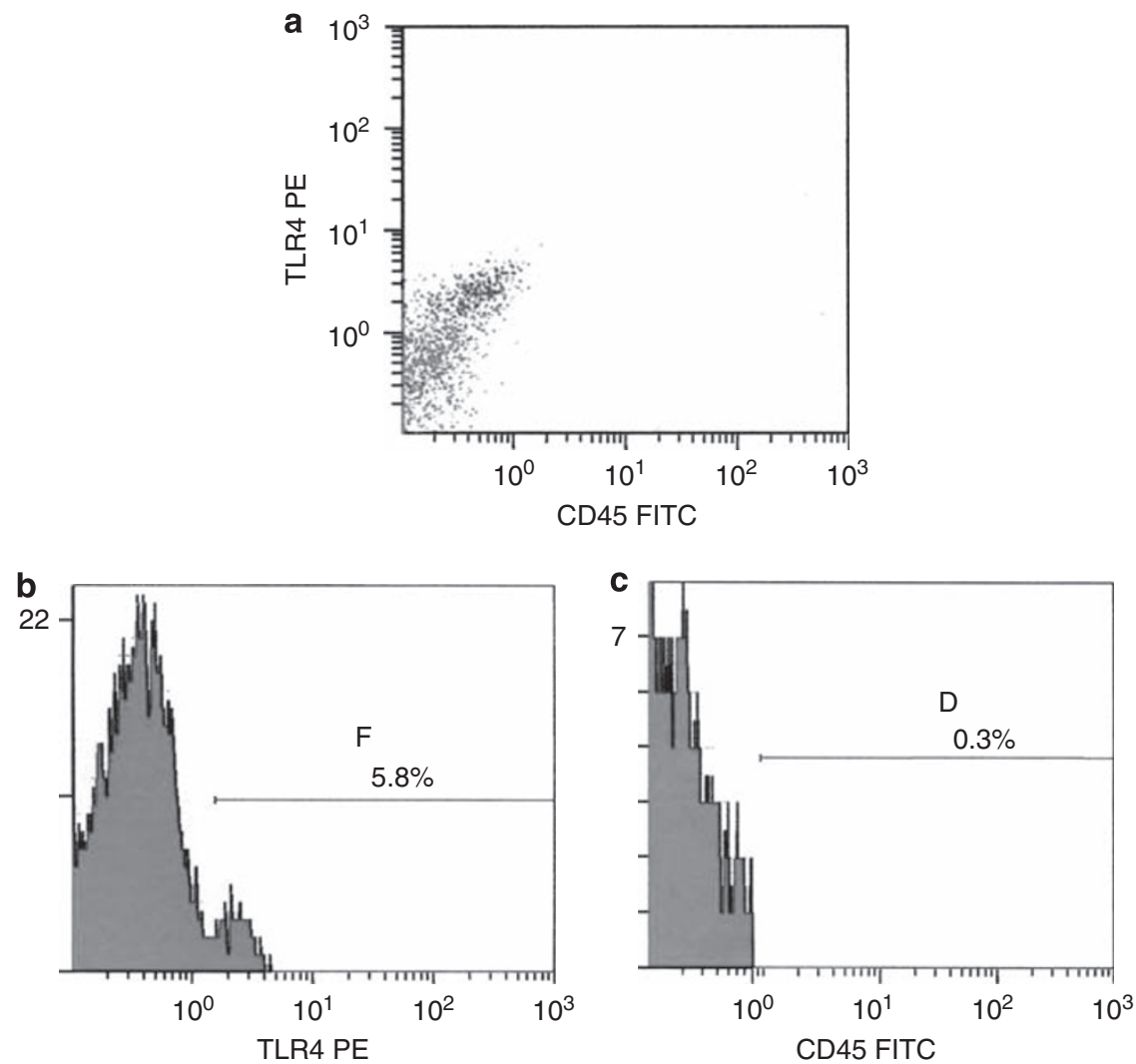

Figure 6 Anti-CD 45 fluorescein isothiocyanate (FITC)/anti-TLR4 PE double stain of SHR heart tissue analyzed by FACS analysis representative for three experiments. The population in blue (a) is TLR4-positive and was back gated to TLR4-positive cells in the histogram in (b). (c) is the histogram plot from the same stain and shows a lack of CD45-positive cells. The fraction of TLR4-expressing cardiac cells was $5.1 \pm 1.4 \%$ with $0.3 \pm 0 \%$ being CD45/TLR4 positive. A full color version of this figure is available at the Hypertension Research journal online.

system. However, to show a direct association, further studies will be needed. Finally, the antihypertensive and anti-inflammatory action of ACE inhibition had no effect on TLR4 expression in a therapeutic but only in a high-dose model. Future experiments have to show whether TLR4 blockade can inhibit the onset and progression of hypertension and whether this may offer additional protection against the development of hypertension and hypertensive heart failure. 


\section{CONFLICT OF INTEREST}

The authors declare no conflict of interest.

1 O'Neill LA. How Toll-like receptors signal: what we know and what we don't know. Curr Opin Immunol 2006; 18: 3-9.

2 Faure E, Thomas L, Xu H, Medvedev A, Equils O, Arditi M. Bacterial lipopolysaccharide and IFN-gamma induce Toll-like receptor 2 and Toll-like receptor 4 expression in human endothelial cells: role of NF-kappa B activation. J Immunol 2001; 166: 2018-2024.

3 Frantz S, Kobzik L, Kim YD, Fukazawa R, Medzhitov R, Lee RT, Kelly RA. Toll4 (TLR4) expression in cardiac myocytes in normal and failing myocardium. J Clin Invest 1999; 104: 271-280.

4 Chen LW, Chang WJ, Chen PH, Liu WC, Hsu CM. TLR ligand decreases mesenteric ischemia and reperfusion injury-induced gut damage through TNF-alpha signaling. Shock (Augusta, Ga) 2008; 30: 563-570.

5 Ha T, Li Y, Hua F, Ma J, Gao X, Kelley J, Zhao A, Haddad GE, Williams DL, William Browder I, Kao RL, Li C. Reduced cardiac hypertrophy in toll-like receptor 4-deficient mice following pressure overload. Cardiovasc Res 2005; 68: 224-234.

6 Yang X, Coriolan D, Murthy V, Schultz K, Golenbock DT, Beasley D. Proinflammatory phenotype of vascular smooth muscle cells: role of efficient Toll-like receptor 4 signaling. Am J Physiol Heart Circ Physiol 2005; 289: H1069-H1076.

7 Zeuke S, Ulmer AJ, Kusumoto S, Katus HA, Heine H. TLR4-mediated inflammatory activation of human coronary artery endothelial cells by LPS. Cardiovasc Res 2002; 56 : 126-134.

8 Rodriguez-Iturbe B, Quiroz Y, Nava M, Bonet L, Chávez M, Herrera-Acosta J, Johnson RJ, Pons HA. Reduction of renal immune cell infiltration results in blood pressure control in genetically hypertensive rats. Am J Physiol Renal Physiol 2002; 282: F191-F201.

9 Rodriguez-Iturbe B, Ferrebuz A, Vanegas V, Quiroz Y, Mezzano S, Vaziri ND. Early and sustained inhibition of nuclear factor-kappaB prevents hypertension in spontaneously hypertensive rats. J Pharmacol Exp Ther 2005; 315: 51-57.

10 Baumann M, Janssen BJ, Hermans JJ, Peutz-Kootstra C, Witzke O, Smits JF, Struijker Boudier HA. Transient AT1 receptor-inhibition in prehypertensive spontaneously hypertensive rats results in maintained cardiac protection until advanced age. $J$ Hypertens 2007; 25: 207-215.

11 Nakazono K, Watanabe N, Matsuno K, Sasaki J, Sato T, Inoue M. Does superoxide underlie the pathogenesis of hypertension? Proc Natl Acad Sci USA 1991; 88: $10045-10048$.

12 Tsan MF, Gao B. Endogenous ligands of Toll-like receptors. J Leukoc Biol 2004; 76: 514-519.

13 Wrenshall LE, Cerra FB, Singh RK, Platt JL. Heparan sulfate initiates signals in murine macrophages leading to divergent biologic outcomes. J Immunol 1995; 154 : 871-880.

14 Johnson GB, Brunn GJ, Kodaira Y, Platt JL. Receptor-mediated monitoring of tissue well-being via detection of soluble heparan sulfate by Toll-like receptor 4. J Immunol 2002; 168: 5233-5239.

15 Tang AH, Brunn GJ, Cascalho M, Platt JL. Pivotal advance: endogenous pathway to SIRS, sepsis, and related conditions. J Leukoc Biol 2007; 82: 282-285.
16 Zemancikova A, Torok J. Effect of chronic nifedipine treatment on blood pressure and adrenergic responses of isolated mesenteric artery in young rats with developing spontaneous hypertension. Physiol Res 2009; 58: 921-925.

17 Heyen JR, Blasi ER, Nikula K, Rocha R, Daust HA, Frierdich G, Van Vleet JF, De Ciechi P, McMahon EG, Rudolph AE. Structural, functional, and molecular characterization of the SHHF model of heart failure. Am J Physiol Heart Circ Physiol 2002; 283: H1775-H1784.

18 Bergman MR, Kao RH, McCune SA, Holycross BJ. Myocardial tumor necrosis factoralpha secretion in hypertensive and heart failure-prone rats. Am J Physiol 1999; 277(2 Pt 2): H543-H550.

19 Schellings MW, Baumann M, van Leeuwen RE, Duisters RF, Janssen SH, Schroen B, Peutz-Kootstra CJ, Heymans S, Pinto YM. Imatinib attenuates end-organ damage in hypertensive homozygous TGR(mRen2)27 rats. Hypertension 2006; 47: 467-474.

20 Otsui K, Inoue N, Kobayashi S, Shiraki R, Honjo T, Takahashi M, Hirata K, Kawashima $\mathrm{S}$, Yokoyama M. Enhanced expression of TLR4 in smooth muscle cells in human atherosclerotic coronary arteries. Heart Vessels 2007; 22: 416-422.

21 Cruzado MC, Risler NR, Miatello RM, Yao G, Schiffrin EL, Touyz RM. Vascular smooth muscle cell $\mathrm{NAD}(\mathrm{P}) \mathrm{H}$ oxidase activity during the development of hypertension: effect of angiotensin II and role of insulinlike growth factor-1 receptor transactivation. Am J Hypertens 2005; 18: 81-87.

22 Lee SK, Arunkumar S, Sirajudeen KN, Singh HJ. Glutathione system in young spontaneously hypertensive rats. J Physiol Biochem 2010; 66: 321-327.

23 Kassan M, Montero MJ, Sevilla MA. Chronic treatment with pravastatin prevents early cardiovascular changes in spontaneously hypertensive rats. Br J Pharmacol 2009; 158: 541-547.

24 Kee HJ, Eom GH, Joung H, Shin S, Kim JR, Cho YK, Choe N, Sim BW, Jo D, Jeong MH, Kim KK, Seo JS, Kook H. Activation of histone deacetylase 2 by inducible heat shock protein 70 in cardiac hypertrophy. Circ Res 2008; 103: 1259-1269.

25 Niizeki T, Takeishi Y, Watanabe T, Nitobe J, Miyashita T, Miyamoto T, Kitahara T, Suzuki S, Sasaki T, Bilim O, Ishino M, Kubota I. Relation of serum heat shock protein 60 level to severity and prognosis in chronic heart failure secondary to ischemic or idiopathic dilated cardiomyopathy. Am J Cardiol 2008; 102: 606-610.

26 Lv J, Jia R, Yang D, Zhu J, Ding G. Candesartan attenuates angiotensin II-induced mesangial cell apoptosis via TLR4/MyD88 pathway. Biochem Biophys Res Commun 2009; 380: 81-86.

27 Ji YY, Wang ZD, Liu JT, Liu N. [Inhibitory effect of fenofibrate on angiotensin II-induced toll-like receptor 4 expression, myeloperoxidase activity and expression in RAW264.7 cells]. Yao Xue Xue Bao 2009; 44: 462-467.

28 Burgess E, Muirhead N, Rene de Cotret P, Chiu A, Pichette V, Tobe S. Supramaximal dose of candesartan in proteinuric renal disease. J Am Soc Nephrol 2009; 20: 893-900.

29 Roger T, Froidevaux C, Le Roy D, Reymond MK, Chanson AL, Mauri D, Burns K, Riederer BM, Akira S, Calandra T. Protection from lethal gram-negative bacterial sepsis by targeting Toll-like receptor 4. Proc Natl Acad Sci USA 2009; 106: 2348-2352.

30 Daubeuf B, Mathison J, Spiller S, Hugues S, Herren S, Ferlin W, Kosco-Vilbois M, Wagner H, Kirschning CJ, Ulevitch R, Elson G. TLR4/MD-2 monoclonal antibody therapy affords protection in experimental models of septic shock. J Immunol 2007; 179: 6107-6114.

31 Fort MM, Mozaffarian A, Stover AG, Correia Jda S, Johnson DA, Crane RT, Ulevitch RJ, Persing DH, Bielefeldt-Ohmann H, Probst P, Jeffery E, Fling SP, Hershberg RM. A synthetic TLR4 antagonist has anti-inflammatory effects in two murine models of inflammatory bowel disease. J Immunol 2005; 174: 6416-6423. 